\title{
DESAIN PENAHAN TANAH DENGAN PERKUATAN GEOTEKSTIL
}

\author{
I Made Putra Dwityagana ${ }^{1}$ \\ ${ }^{1}$ Program Studi Teknik Sipil FT Unhi \\ dedesamuh@gmail.com
}

\begin{abstract}
ABSTRAK
Kondisi lereng dengan beban yang besar dan kemiringan yang curam dapat menyebabkan terjadinya kelongsoran. Diperlukan sebuah perkuatan lereng, salah satunya yaitu dengan geotekstil. Geotekstil sering digunakan karena memiliki beberapa keunggulan, antara lain mudah dalam pelaksanaan dan dapat meningkatkan stabilitas lereng secara efektif. Studi kasus mengenai desain penahan tanah dengan perkuatan geotekstil ini dilakukan di Jalan Raya Bedugul-Singaraja, Desa Pancasari, Kecamatan Sukasada, Kabupaten Buleleng. Penelitian ini bertujuan untuk mengetahui desain penahan tanah dengan perkuatan geotekstil pada lokasi tersebut. Adapun desain yang dimaksud meliputi panjang geotekstil yang diperlukan (panjang penjangkaran, panjang nonacting dan panjang overlap), jarak vertikal antar geotekstil (Sv).

Data-data yang dibutuhkan adalah data primer meliputi : $\gamma$ tanah, kohesi tanah (c), sudut geser $(\phi)$ tanah. Analisis desain dilakukan dengan perhitungan manual dengan menggunakan metode Rankine. Analisis data meliputi spasi antar lapisan geosintetik $\left(\mathrm{S}_{\mathrm{v}}\right)$, tegangan izin $\left(\mathrm{T}_{\mathrm{all}}\right)$, tegangan lateral tanah $\left(\sigma_{\mathrm{h}}\right)$, kuat tarik geosintetik yang dibutuhkan $\left(\mathrm{P}_{\mathrm{req}}\right)$, panjang penjangkaran + panjang nonacting $(\mathrm{L})$, panjang overlap $\left(\mathrm{L}_{\mathrm{o}}\right)$, tekanan aktif tanah $\left(\mathrm{P}_{\mathrm{a}}\right)$. Selanjutnya diperlukan analisis untuk menghitung stabilitas terhadap faktor penyebab kegagalannya, yaitu kontrol stabilitas internal dan stabilitas eksternal.

Berdasarkan hasil penelitian diperoleh bahwa spasi antar lapisan geotekstil berturut-turut sebesar $0,30 \mathrm{~m}, 0,40 \mathrm{~m}, 0,50 \mathrm{~m}$. Preq sebesar $55 \mathrm{kN} / \mathrm{m}$. Diperoleh hasil $\mathrm{L}$ dengan panjang 3,00 m pada kedalaman $0,50 \mathrm{~m}, 1,00 \mathrm{~m}$, $1,50 \mathrm{~m}$, dan $1,90 \mathrm{~m}$, serta $\mathrm{L}$ dengan panjang $2,00 \mathrm{~m}$ pada kedalaman $2,30 \mathrm{~m}$, $2,70 \mathrm{~m}, 3,00 \mathrm{~m}, 3,30 \mathrm{~m}$, dan $3,60 \mathrm{~m}$. $\mathrm{L}_{\mathrm{o}}$ diperoleh hasil yang sama yaitu $1,00 \mathrm{~m}$ pada setiap kedalaman.

Hasil penelitian yang diperoleh telah memenuhi kontrol stabilitas eksternal yang meliputi kegagalan geser, kegagalan guling, kegagalan daya dukung tanah dasar serta kontrol terhadap stabilitas internal yang meliputi putusnya tulangan dan tercabutnya tulangan.
\end{abstract}

Kata kunci : desain penahan tanah, perkuatan tanah, geotekstil. 


\section{PENDAHULUAN}

Peristiwa longsor terjadi karena geseran tanah yang meningkat sudah tidak mampu lagi ditahan oleh tanah. Salah satu daerah di Bali yang sering terjadi longsor yaitu kawasan Jalan Raya Bedugul-Singaraja, Desa Pancasari, Kecamatan Sukasada, Kabupaten Buleleng. Berdasarkan data dari web resmi dari Badan Penanggulangan Bencana Daerah (BPBD) Kabupaten Buleleng sepanjang tahun 2012 sampai Februari 2013 telah terjadi kasus longsor sebanyak dua puluh dua (22) kali pada titik yang berbeda (BPBD Kabupaten Buleleng, 2013).

Salah satu konsep untuk menindaklanjuti longsor tersebut yaitu penambahan suatu bahan ke dalam tanah untuk memikul gaya tarik yang dipikul oleh lereng. Seiring perkembangan zaman, timbullah salah satu material konstruksi dengan nama geotekstil yang fungsinya sebagai separasi, perkuatan. Kombinasi antara material tanah (yang baik dalam memikul gaya tekan tapi lemah dalam gaya tarik) dengan material geotekstil (yang baik dalam memikul gaya tarik tapi lemah dalam memikul gaya tekan) ini berhasil dengan baik.

Berdasarkan penjelasan di atas, diharapkan adanya perencanaan terkait dengan penggunaan geotekstil di lapangan. Maka dari itu diperlukan sebuah desain penahan tanah dengan menggunakan bahan geotekstil sebagai perkuatan.

\section{Rumusan Masalah}

Sesuai dengan latar belakang yang telah diuraikan di atas, maka permasalahan yang akan diangkat pada penyusunan jurnal ilmiah ini adalah bagaimana mendesain penahan tanah dengan perkuatan geotekstil.

\section{Tujuan Penelitian}

Adapun tujuan yang hendak dicapai dalam penulisan jurnal ilmiah ini adalah menguraikan secara jelas desain penahan tanah dengan perkuatan geotekstil.

\section{MATERI DAN METODE}

\section{Perkuatan pada Tanah}

Tanah berperkuatan pada penahan tanah adalah konstruksi material yang terdiri dari material timbunan friksional dan lembaran perkuatan (perkuatan) linear, biasanya ditempatkan secara horisontal. Sistem perkuatan dapat menahan gaya tarik yang tinggi, menahan deformasi lateral massa tanah yang diperkuat. Struktur perkuatan tanah bertulang: material timbunan, lembaran perkuatan (perkuatan) yang linear, digabungkan dengan timbunan, membentuk massa tanah berperkuatan, dan lapisan luar, yang mempunyai peranan mencegah material timbunan di belakang dinding penahan dari kelongsoran.

\section{Definisi Geotekstil}

Geotekstil adalah bahan polimer yang lulus air. Dapat berupa tenunan (woven), rajutan (nonwoven). Digunakan dalam pekerjaan geoteknik dan teknik sipil lainnya.

\section{Fungsi \& Aplikasi Geotekstil}

Geotekstil memiliki fungsi sebagai berikut:

1. Separator: bahan Geotekstil digunakan di antara dua material tanah yang tidak sejenis untuk mencegah terjadi pencampuran material.

2. Perkuatan: sifat tarik bahan Geotekstil dimanfaatkan untuk menahan tegangan atau deformasi pada struktur tanah.

\section{Observasi Awal}

Lokasi penelitian ini berada di Jalan Raya Bedugul-Singaraja, Desa Pancasari, Kecamatan Sukasada, Kabupaten Buleleng.

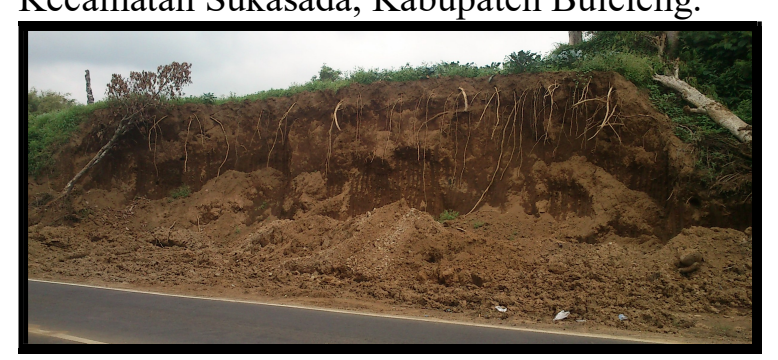

Gambar 1. Lokasi studi kasus

Metode Pengumpulan Data

a. Pemeriksaan Berat Jenis Tanah 


$$
\begin{aligned}
& \text { Gs }=\frac{\text { Berat Volume Butir }- \text { ButirTanah }}{\text { Berat Volume Air }} \\
& =\frac{\left(W_{2}-W_{1}\right)}{\left(W_{2}-W_{1}\right)-\left(W_{3}-W_{4}\right)} \ldots \ldots \ldots \ldots \ldots \ldots
\end{aligned}
$$

b. Pemadatan Tanah (Soil Compaction)

$$
\gamma z a v=\frac{\gamma w}{w+\frac{1}{G s}}
$$

Keterangan :

$\gamma_{z a v}=$ Berat volume saat kadar udara nol

Gs $=$ Berat spesifik butiran padat tanah

$\gamma_{w}=$ Berat volume air

$\mathrm{W}=$ Kadar air

c. Pemeriksaan Tekan Bebas (Unconfined Compression Test)

Sudut geser $(\phi)$ dapat dihitung dengan persamaan:

$\phi=\left(\alpha-45^{0}\right) \times 2$

dimana :

$\alpha=$ sudut pecah tanah saat tes

Kohesi (cu) dapat dihitung dengan persamaan:

$$
\mathrm{cu}=\frac{q_{u}}{2}
$$

Perancangan Desain Penahan Tanah Dengan Perkuatan Geotekstil

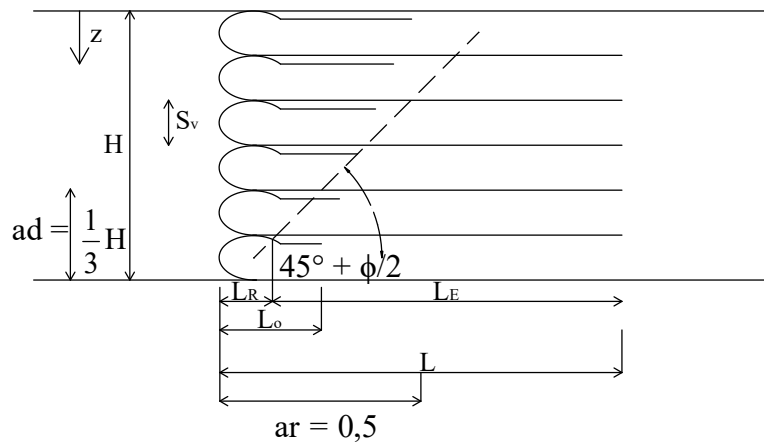

Gambar 2. Konsep Desain Rankine
$\mathrm{L}_{\mathrm{E}}$ : panjang penjangkaran

$\mathrm{L}$ : panjang penjangkaran + panjang nonacting

$\mathrm{Z}$ : kedalaman titik yang ditinjau dari permukaan tanah

$\Phi^{\prime}$ : sudut geser tanah

Perhitungan spasi antar lapisan geosintetik

$$
S_{v}=\frac{T_{\text {all }}}{\sigma_{h}^{\prime} \cdot \times F S}
$$

....(5)

Dimana :

$\mathrm{S}_{\mathrm{v}}$ : spasi antar lapisan geometrik

$\mathrm{T}_{\text {all }}$ : tegangan izin

$\sigma_{h}^{\prime}:$ tekanan lateral tanah pada kedalaman tertentu

FS : faktor keamanan $(1,3-1,5)$

Perhitungan tegangan izin ( $\left.T_{\text {all }}\right)$

$T_{\text {all }}=T_{\text {ult }}\left(\frac{1}{F S_{I D} \times F S_{C R} \times F S_{C D} \times F S_{B D}}\right) \cdots \cdots \cdots \cdots \cdots$

Dimana :

$\mathrm{T}_{\text {ult }}$ : tegangan tarik batas geosintetik

FS ID: faktor parsial kerusakan instalasi saat konstruksi $(1,1-2,0)$

$\mathrm{FS}_{\mathrm{CR}}$ : faktor parsial akibat rangkak (creep) $(2,0-4,0)$

$\mathrm{FS}_{\mathrm{CD}}$ : faktor parsial akibat degradasi kimia $(1,0-1,5)$

$\mathrm{FS}_{\mathrm{BD}}$ : faktor parsial akibat degradasi biologi $(1,0-1,3)$

Perhitungan panjang penjangkaran ditambah panjang nonacting (L)

$L=L_{E}+L_{R}$

Dimana :

$\mathrm{L}_{\mathrm{E}}$ : embedment length / panjang penjangkaran

$\mathrm{L}_{\mathrm{R}}$ : nonacting lengths / panjang nonacting

\section{Perhitungan panjang overlap $\left(\mathrm{L}_{0}\right)$}

$$
L_{o}=\frac{S_{v} \cdot \sigma_{h}^{\prime} \cdot F S}{4(c+\gamma \cdot z \tan \delta)}
$$


Dimana :

FS : faktor keamanan $(1,3-1,5)$

Perhitungan tekanan aktif tanah $\left(\mathbf{P}_{\mathbf{a}}\right)$

$P_{a}=0,5 \cdot \gamma \cdot H^{2} \cdot K_{a}$

Dimana :

$\mathrm{P}_{\mathrm{a}}$ : tekanan aktif tanah

$\mathrm{K}_{\mathrm{a}}$ : koefisien tekanan aktif tanah, $K_{a}=\tan ^{2}\left(45^{\circ}-\frac{\phi}{2}\right)$

\section{Stabilitas Eksternal}

Faktor Keamanan Terhadap Kegagalan Geser

$$
F K_{\text {geser }}=\frac{c \cdot L_{e}+Q \tan \delta}{P_{a}}>1,5
$$

Dimana :

Q: gaya karena beban tanah sendiri $\left(Q=L_{E} \times H \times \gamma\right)$

$\mathrm{P}_{\mathrm{a}}$ : tekanan yang menyebabkan gaya geser

$\delta$ : sudut friksi antara tanah dengan geosintetik

Faktor Keamanan Terhadap Kegagalan Guling

$$
F S_{\text {guling }}=\frac{Q \cdot a r}{P_{a} \cdot a d}>2
$$

Dimana :

$Q$ :gaya karena beban tanah sendiri $\left(Q=L_{E} \times H \times \gamma\right)$

ar : $0,5 \mathrm{~L}$

$\mathrm{P}_{\mathrm{a}}$ : tekanan yang menyebabkan gaya geser ad : $\frac{1}{3} \mathrm{H}$

Faktor Keamanan Terhadap Kegagalan Daya Dukung Tanah Dasar

$$
\begin{aligned}
& F K_{\text {tan } \text { ah pondasi }}=\frac{q_{u l t}}{q}>3 \ldots . \\
& q_{u l t}=c \cdot N_{c}+q \cdot N_{q}+0,5 \cdot \gamma \cdot B \cdot N_{\gamma}
\end{aligned}
$$

Dimana :

$q_{\text {ult }}:$ daya dukung tanah)

Q : berat tanah

B : lebar dasar pondasi yang kontak dengan tanah

$N_{c}$ : koefisien daya dukung untuk kohesi

$\mathrm{N}_{\mathrm{q}} \quad$ : koefisien daya dukung untuk berat tanah (beban)

$\mathrm{N}_{\gamma}$ : koefisien daya dukung untuk berat jenis tanah

Faktor Keamanan Terhadap Kegagalan Stabilitas Global

$$
F S_{\text {tulangan }}=F S_{\text {non-tulangan }}+\left(\frac{M_{g}}{M_{D}}\right) \ldots \ldots \ldots \ldots
$$

Stabilitas Internal

Faktor Keamanan Terhadap Putusnya Perkuatan

$$
F K_{O S}=\frac{T_{\text {all }}}{T_{\text {pendorong } i}}
$$

Dimana :

$\mathrm{T}_{\text {all }}$ : tegangan yang dimiliki tiap geotekstil

$\mathrm{T}_{\text {pendorong I }}$ :tegangan tarik maksimum pada tiap geotekstil

Faktor Keamanan

Terhadap

Tercabutnya Perkuatan

$F K_{P O}=\frac{T_{\text {penahan } i}}{T_{\text {pendorong } i}}$

$T_{\text {penahani }}=2 \times L_{a i} \times \sigma_{h}^{\prime} \times \tan \delta$

Dimana :

$\mathrm{T}_{\text {penahan } \mathrm{I}} \quad$ : tegangan penahan yang mencegah geotekstil tercabut dari tanah yang menjepitnya

$\mathrm{T}_{\text {pendorong I }}$ : tegangan tarik maksimum pada tiap geotekstil

$\mathrm{L}_{\mathrm{ai}} \quad$ : panjang geotekstil penahan (panjang zona angkur di belakang bidang runtuh)

$\delta \quad:$ sudut friksi antara tanah dengan geotekstil

\section{HASIL DAN PEMBAHASAN DESAIN \\ Lapisan perkuatan yang dipakai}

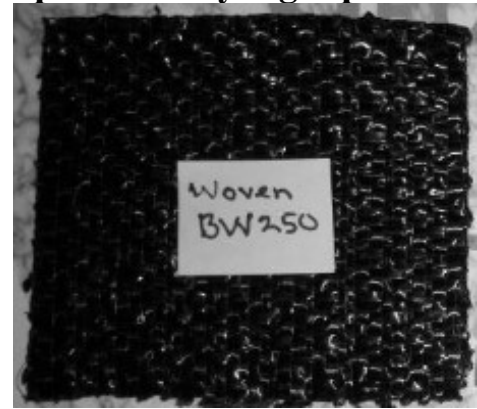

Gambar 3. Geotekstil yang digunakan 
Geotekstil BW-250 dengan tensile sebesar $25 \mathrm{kN} / \mathrm{m}$.

\section{Data Primer dari Hasil Laboratorium $\mathrm{c}=8420 \mathrm{~N} / \mathrm{m}^{2}$ \\ $\phi=28^{\circ}$ \\ $\gamma=1,265 \mathrm{gr} / \mathrm{cm}^{3}$}

\section{Interaksi Tanah Dan Geotekstil}

$\frac{2}{3} \times \tan \phi=\frac{2}{3} \times \tan 28^{\circ}=0,355$

\section{Perencanaan Desain}

Dirancang sebuah desain penahan tanah dengan menggunakan perkuatan geotekstil. Desain penahan tanah dibuat setinggi lereng yang terletak pada daerah Jalan Raya Bedugul-Singaraja, Desa Pancasari, Kecamatan Sukasada, Kabupaten Buleleng, dimana tinggi lereng adalah 3,60 meter. dengan memasukkan air tanah, dimana direncanakan tinggi muka air tanah setinggi 1,70 meter. Direncanakan penahan tanah mampu menahan beban mati sebesar 5000 $\mathrm{N} / \mathrm{m}^{2}$ serta beban hidup berupa beban orang dewasa sebesar $800 \mathrm{~N} / \mathrm{m}^{2}$. Tanah yang dipakai merupakan tanah timbunan setempat dimana sampel tanahnya telah diteliti di laboratorium.

\section{Koefisien Tanah Aktif $\left(K_{a}\right)$}

$$
\begin{aligned}
\mathrm{K}_{\mathrm{a}} & =\tan ^{2}\left(45^{\circ}-\phi / 2\right) \\
& =\tan ^{2}\left(45^{\circ}-28^{\circ} / 2\right) \\
& =0,361
\end{aligned}
$$

\section{Tegangan Izin $\left(\mathrm{T}_{\text {all }}\right)$}

$$
\begin{aligned}
T_{\text {all }} & =T_{\text {ult }}\left(\frac{1}{F S_{I D} \times F S_{C R} \times F S_{C D} \times F S_{B D}}\right) \\
& =55000\left(\frac{1}{1,2 \times 2,5 \times 1,2 \times 1,2}\right) \\
& =16700 \mathrm{~N} / \mathrm{m}
\end{aligned}
$$

\section{PerhitunganTegangan Lateral Tanah}

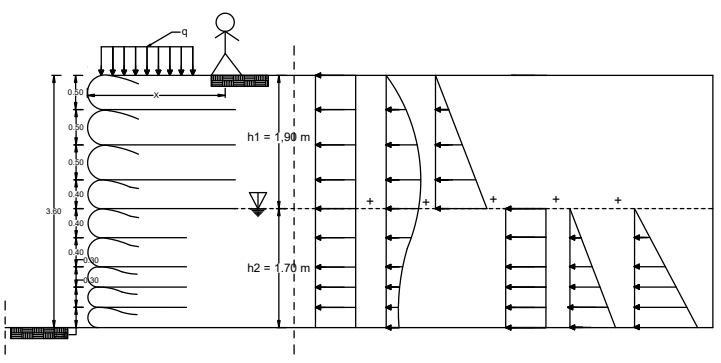

Gambar 4. Diagram tegangan lateral tanah

Perhitungan Tekanan Lateral per Kedalaman (z)

Ditinjau pada Kedalaman z = 3,60 m (Dibawah Muka Air)

a. Tekanan Lateral akibat Beban Merata

$$
\begin{aligned}
\sigma_{h q_{1}}^{\prime}= & K a \times q \\
& =0,361 \times 5000 \\
& =1805 \mathrm{~N} / \mathrm{m}^{2}
\end{aligned}
$$

b. Tekanan Lateral akibat Beban Hidup (Terpusat)

$$
\begin{aligned}
\sigma_{h l}^{\prime} & =P \frac{x^{2} z}{R^{5}} \\
& =800 \frac{2^{2} \times 3,60}{4,12^{5}} \\
& =9,70 \mathrm{~N} / \mathrm{m}^{2}
\end{aligned}
$$

c. Tekanan Lateral akibat Beban Tanah Diatas Muka Air

$$
\begin{aligned}
\sigma_{h s 1}^{\prime} & =\gamma \times K_{a} \times z \\
& =12650 \times 0,361 \times 3,60 \\
& =16439,94 \mathrm{~N} / \mathrm{m}^{2}
\end{aligned}
$$

d. Tekanan Lateral akibat Beban Diatasnya

$$
\begin{aligned}
\sigma_{h q_{2}}^{\prime} & =K a \times \gamma \times z \\
& =0,361 \times 12650 \times 3,60 \\
& =16439,94 \mathrm{~N} / \mathrm{m}^{2}
\end{aligned}
$$

e. Tekanan Lateral akibat Beban Tanah Dibawah Muka Air

$$
\begin{aligned}
\sigma_{h s 2}^{\prime}= & \left(\gamma-\gamma_{w}\right) \times K_{a} \times z \\
& =(12650-10000) \times 0,361 \times 1,70 \\
& =1626,305 \mathrm{~N} / \mathrm{m}^{2}
\end{aligned}
$$

f. Tekanan Lateral akibat Pengaruh Air Tanah

$$
\begin{aligned}
\sigma_{h w}^{\prime}= & z \times \gamma_{w} \\
& =1,70 \times 10000 \\
& =17000 \mathrm{~N} / \mathrm{m}^{2}
\end{aligned}
$$

Persamaan Tekanan Lateral Total

$$
\begin{aligned}
& \sigma_{h}^{\prime}=\sigma_{h q 1}+\sigma_{h l}+\sigma_{h s 1}+\sigma_{h q 1}+\sigma_{h s 2}+\sigma_{h w} \\
& =1805+9,70+16439,94+16439,94+662,796+6137 \mathrm{~N} / \mathrm{m}^{2} \\
& =53320,91 \mathrm{~N} / \mathrm{m}^{2}
\end{aligned}
$$


Dengan perhitungan yang sama, didapatkan hasil sesuai dengan tabel di bawah.

Tabel 1. Rangkuman tekanan lateral tanah per kedalaman $\mathrm{z}$ dengan air tanah

\begin{tabular}{|c|c|c|c|c|r|r|r|}
\hline $\mathrm{z}$ & $\sigma_{h q 1}$ & $\sigma_{h l}$ & $\sigma_{h s 1}^{\prime}$ & $\sigma_{h q 1}^{\prime}$ & $\sigma_{h s 2}^{\prime}$ & $\sigma_{h w}^{\prime}$ & $\sigma_{h}^{\prime}$ \\
& $\mathrm{N} / \mathrm{m}^{2}$ & $\mathrm{~N} / \mathrm{m}^{2}$ & $\mathrm{~N} / \mathrm{m}^{2}$ & $\mathrm{~N} / \mathrm{m}^{2}$ & $\mathrm{~N} / \mathrm{m}^{2}$ & $\mathrm{~N} / \mathrm{m}^{2}$ & $\mathrm{~N} / \mathrm{m}^{2}$ \\
\hline 0,5 & 1805 & 42,96 & 2283,32 & 2283,32 & - & - & 6414,6 \\
\hline 1,0 & 1805 & 57,24 & 4566,65 & 4566,65 & - & - & 10995,5 \\
\hline 1,5 & 1805 & 49,15 & 6849,98 & 6849,98 & - & - & 15554,1 \\
\hline 1,9 & 1805 & 38,05 & 8676,64 & 8676,64 & - & - & 19196,3 \\
\hline 2,3 & 1805 & 27,97 & 10503,3 & 10503,3 & 382,7 & 4000 & 27222,2 \\
\hline 2,7 & 1805 & 20,17 & 12329,9 & 12329,9 & 765,3 & 8000 & 35250,4 \\
\hline 3,0 & 1805 & 15,75 & 13699,9 & 13699,9 & 1052,3 & 11000 & 41272,9 \\
\hline 3,3 & 1805 & 12,34 & 14613,3 & 14613,3 & 1339,3 & 14000 & 47296,5 \\
\hline 3,6 & 1805 & 9,72 & 16439,9 & 16439,9 & 1626,3 & 17000 & 53320,9 \\
\hline
\end{tabular}

Menghitung Spasi Antar Perkuatan Geotekstil ( $\left.\mathbf{S}_{\mathbf{v}}\right)$

Dengan trial and error, dicoba memakai $\mathrm{S}_{\mathrm{v}}$ $=0,30 \mathrm{~m}$ di kedalaman $\mathrm{z}=3,60 \mathrm{~m}$

$$
\begin{aligned}
S_{v} & =\frac{T_{\text {all }}}{\sigma_{h}^{\prime} \cdot \times F S} \\
& =\frac{16700}{53320,91 \times 1,4} \\
& =0,305 \mathrm{~m} \quad(\mathrm{OK})
\end{aligned}
$$

Hasil perhitungan spasi antar geotekstil dapat dilihat pada gambar 7 .

\section{Panjang Penjangkaran Ditambah}

Panjang Nonacting (L)

Ditinjau pada kedalaman $\mathrm{z}=\mathbf{0 , 5 0}$ meter

$$
\begin{aligned}
L_{R}= & (H-z) \tan \left(45^{\circ}-\frac{\varphi}{2}\right) \\
& =(3,60-0,50) \tan \left(45^{\circ}-\frac{28^{\circ}}{2}\right) \\
& =1,86 m \\
L_{E} & =\frac{S_{v} \sigma_{h} F S}{2(8420+\gamma . z \tan \delta)} \\
& =\frac{0,50 \times 6414,618 \times 1,4}{2(8420+12650 \times 0,50 \times 0,355)} \\
& =0,197 m
\end{aligned}
$$

Karena panjang $\mathrm{L}_{\mathrm{E}}$ minimum $=1$ meter, maka yang dipakai adalah $\mathrm{L}_{\mathrm{E}}$ minimum

$$
\begin{aligned}
L & =L_{R}+L_{E} \\
& =1,86+1,0 \\
& =2,86 \mathrm{~m}
\end{aligned}
$$

Hasil perhitungan lengkap dapat dilihat pada tabel.

Menghitung Panjang Overlap (Lo)

Panjang Overlap (Lo) Ditinjau pada kedalaman $\mathrm{z}=\mathbf{0 , 5 0}$ meter

$$
\begin{aligned}
L_{E} & =\frac{S_{v} \sigma_{h} F S}{4(8420+\gamma . z \tan \delta)} \\
& =\frac{0,50 \times 6414,618 \times 1,4}{4(8420+12650 \times 0,50 \times 0,355)} \\
& =0,0985 \mathrm{~m}
\end{aligned}
$$

Karena panjang $\mathrm{L}_{\mathrm{o}}$ minimum $=1$ meter, maka yang dipakai adalah $\mathrm{L}_{\mathrm{o}}$ minimum.

Tabel 2. Rangkuman perhitungan panjang perkuatan geotekstil

\begin{tabular}{|l|l|l|l|l|l|l|}
\hline $\begin{array}{l}\mathrm{z} \\
(\mathrm{m})\end{array}$ & $\begin{array}{l}\mathrm{Sv} \\
(\mathrm{m})\end{array}$ & $\begin{array}{l}\mathrm{L}_{\mathrm{e}} \\
(\mathrm{m})\end{array}$ & $\begin{array}{l}\mathrm{L}_{\mathrm{e}} \\
\mathrm{min} \\
(\mathrm{m})\end{array}$ & $\begin{array}{l}\mathrm{L}_{\mathrm{r}} \\
(\mathrm{m})\end{array}$ & $\begin{array}{l}\mathrm{L} \\
(\mathrm{m})\end{array}$ & $\begin{array}{l}\mathrm{L} \\
\text { dipakai } \\
(\mathrm{m})\end{array}$ \\
\hline 0,50 & 0,50 & 0,045 & 1,00 & 1,86 & 2,86 & 3,00 \\
\hline 1,00 & 0,50 & 0,066 & 1,00 & 1,56 & 2,56 & 3,00 \\
\hline 1,50 & 0,50 & 0,090 & 1,00 & 1,26 & 2,26 & 3,00 \\
\hline 1,90 & 0,40 & 0,095 & 1,00 & 1,02 & 2,02 & 3,00 \\
\hline 2,30 & 0,40 & 0,120 & 1,00 & 0,78 & 1,78 & 2,00 \\
\hline 2,70 & 0,40 & 0,132 & 1,00 & 0,54 & 1,54 & 2,00 \\
\hline 3,00 & 0,30 & 0,141 & 1,00 & 0,36 & 1,36 & 2,00 \\
\hline 3,30 & 0,30 & 0,156 & 1,00 & 0,18 & 1,18 & 2,00 \\
\hline 3,60 & 0,30 & 0,174 & 1,00 & 0,00 & 1,00 & 2,00 \\
\hline
\end{tabular}

Dari tabel tersebut, dapat digambarkan panjang perkuatan sebagai berikut:

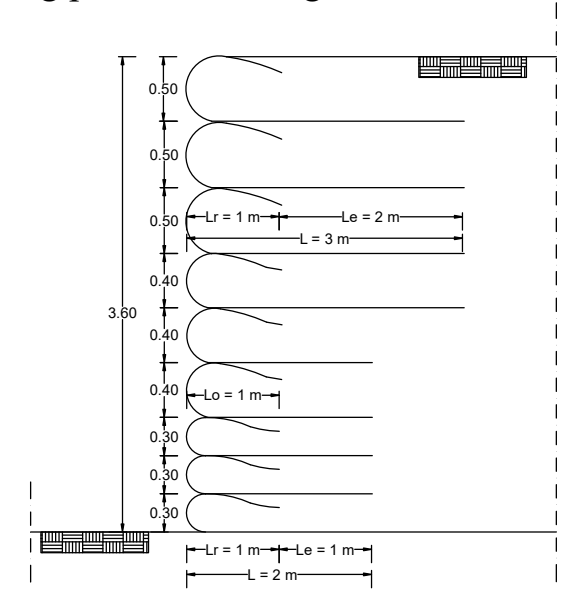

Gambar 7. Panjang penjangkaran dan panjang overlap per kedalaman 


\section{Kontrol Stabilitas}

Tabel 3. Perhitungan tekanan dan momen

\begin{tabular}{|c|c|}
\hline Tekanan Tanah $(\mathrm{Pa})$ & Momen Terhadap A \\
\hline $\begin{array}{l}\mathrm{Pa}_{1}=\mathrm{Ka} \cdot \mathrm{q} \cdot \mathrm{H} \\
=0,361 \cdot 5000 \cdot 3,60 \\
=6498 \mathrm{~N} / \mathrm{m}\end{array}$ & $\begin{array}{l}\mathrm{M}_{1}=6498.1,80 \\
=11696,4 \text { N.m }\end{array}$ \\
\hline $\begin{array}{l}\mathrm{Pa}_{2}=\mathrm{P} \cdot \mathrm{x}^{2} \cdot \mathrm{H}^{2} / \mathrm{R}^{5} \\
=800 \cdot 2^{2} \cdot 3,60^{2} / 4,12^{5} \\
=34,94 \mathrm{~N} / \mathrm{m}\end{array}$ & $\begin{array}{l}\mathrm{M}_{2}=34,94.2,41 \\
=84,21 \text { N.m }\end{array}$ \\
\hline $\begin{array}{l}\mathrm{Pa}_{3}=\mathrm{Ka} \cdot \gamma \cdot \mathrm{h}_{1}^{2} \cdot \cos 20^{\circ} / 2 \\
=0,361 \cdot 12650 \cdot 1,90^{2} \cdot 0,94 / 2 \\
=7745,71 \mathrm{~N} / \mathrm{m}\end{array}$ & $\begin{array}{l}\mathrm{M}_{3}=7745,71.2,33 \\
=18047,50 \text { N.m }\end{array}$ \\
\hline $\begin{array}{l}\mathrm{Pa}_{4}=\mathrm{Ka} \cdot \gamma \cdot \mathrm{h}_{1} \cdot \mathrm{h}_{2} \cdot \cos 20^{\circ} \\
=0,361 \cdot 12650 \cdot 1,9 \cdot 1,7 \cdot 0,94 \\
=13860,73 \mathrm{~N} / \mathrm{m}\end{array}$ & $\begin{array}{l}\mathrm{M}_{4}=13860,73.0,85 \\
=11781,62 \mathrm{~N} \cdot \mathrm{m}\end{array}$ \\
\hline $\begin{array}{l}\mathrm{Pa}_{5}=\mathrm{Ka} \cdot \gamma^{\prime} \cdot \mathrm{h}_{2}^{2} / 2 \\
=0,361 \cdot 2650 \cdot 1,70^{2} \cdot \cos 20^{\circ} / 2 \\
=1298,99 \mathrm{~N} / \mathrm{m}\end{array}$ & $\begin{array}{l}\mathrm{M}_{5}=1298,99 \cdot 0,57 \\
=740,42 \mathrm{~N} \cdot \mathrm{m}\end{array}$ \\
\hline $\begin{array}{l}\mathrm{Pa}_{6}=\gamma_{\mathrm{w}} \cdot \mathrm{h}_{2}^{2} / 2 \\
=10000 \cdot 1,70^{2} / 2 \\
=14450 \mathrm{~N} / \mathrm{m}\end{array}$ & $\begin{array}{l}M_{6}=14450.0,57 \\
=8236,5 \text { N.m }\end{array}$ \\
\hline$\Sigma \mathrm{Pa}=43888,37 \mathrm{~N} / \mathrm{m}$ & $\Sigma \mathrm{M}=50586,65 \mathrm{~N} \cdot \mathrm{m}$ \\
\hline
\end{tabular}

Perhitungan tegangan lateral tanah ke arah vertikal :

$$
\begin{aligned}
\mathrm{Pa}_{3} \mathrm{x} \sin \delta & =\frac{\mathrm{Ka} \times \gamma \times h_{1}^{2} \times \sin \delta}{2} \\
& =\frac{0,361 \times 12650 \times 1,90^{2} \times \sin 20^{\circ}}{2} \\
& =2819,21 \mathrm{~N} / \mathrm{m}
\end{aligned}
$$

$\mathrm{Pa}_{4} \mathrm{x} \sin \delta=\mathrm{Ka} \times \gamma \times h_{1} \times h_{2 \times} \sin \delta$

$$
\begin{aligned}
& =0,361 \times 12650 \times 1,90 \times 1,70 \times \sin 20^{\circ} \\
& =5044,89 \mathrm{~N} / \mathrm{m}
\end{aligned}
$$

$\mathrm{Pa}_{5} \mathrm{x} \sin \delta=\frac{\mathrm{Ka} \times \gamma^{\prime} \times h_{2}^{2} \times \sin \delta}{2}$

$$
\begin{aligned}
& =\frac{0,361 \times(12650-10000) \times 1,70^{2} \times \sin 20^{\circ}}{2} \\
& =472,79 \mathrm{~N} / \mathrm{m} \\
& \Sigma P_{a} \times \sin \delta=2819,21+5044,89+472,79 \\
& =8336,89 \mathrm{~N} / \mathrm{m}
\end{aligned}
$$

\section{Kontrol Stabilitas Eksternal Faktor Keamanan Terhadap Kegagalan Geser}

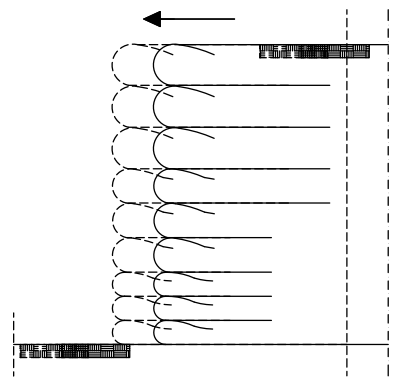

Gambar 8. Ilustrasi kegagalan geser

$$
\begin{aligned}
& F K_{\text {geser }} \geq 1,5 \\
& F K_{\text {geser }}=\frac{(c+Q) \times L_{e} \times \tan \delta}{\Sigma P_{a}}>1,5 \\
& =\frac{\left[c_{a}+\left(\frac{w_{1}+w_{2}+P_{a} \sin \phi+q . L}{2}\right) \tan \delta\right] \times 2}{\Sigma P_{a}}>1,5 \\
& =\frac{\left[8420+\left(\frac{(91080)+(24035)+(8336,89)+(5000)}{2}\right) 0,355\right] \times 2}{43888,37}>1,5
\end{aligned}
$$$$
=1,658>1,5 \quad(O K)
$$

Faktor Keamanan Terhadap Kegagalan Guling

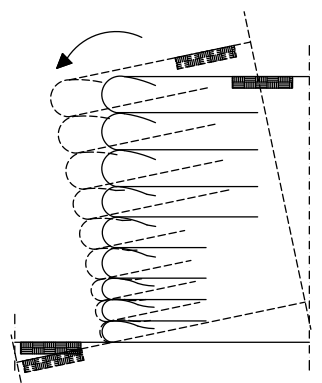

Gambar 9. Ilustrasi kegagalan guling

$$
F S_{\text {guling }}=\sum \frac{Q \cdot a r}{\Sigma M}>2,0
$$

$$
\begin{aligned}
& =\frac{w_{1} . x_{1}+w_{2} . . x_{2}+\Sigma P_{a} \sin \delta . L+\left(q . x_{1}\right)}{\Sigma M}>2,0 \\
& =\frac{(3,60 \times 2 \times 12650 \times 1)+(1,90 \times 1 \times 12650 \times 2,5)+(8336,89 \times 3)+(5000 \times 1)}{50586,65}>2 \\
& =3,58>2,0 \quad(O K) \quad
\end{aligned}
$$


Faktor Keamanan Tanah Dasar

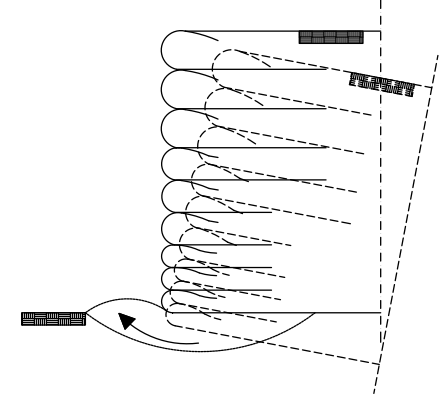
dasar

Gambar 10. Ilustrasi kegagalan tanah

$$
\begin{aligned}
F K_{\text {tan ah pondasi }}=\frac{q_{u l t}}{q_{a c t}}>2 \\
=\frac{c . N_{c}+q \cdot N_{q}+0,5 \cdot \gamma \cdot B \cdot N_{\gamma}}{(\gamma \cdot H)+c}>2 \\
=\frac{8420 \times 25,8+0+0,5 \times 12650 \times 2 \times 11,19}{(12650 \times 3,6)+8420}>2,0 \\
=\frac{1123034,2}{88988}>2,0 \\
=6,65>2,0 \quad(\text { OK })
\end{aligned}
$$

Faktor Keamanan Terhadap Kegagalan Stabilitas Global

Perhitungan Faktor Keamanan terhadap Stabilitas Global Nonperkuatan

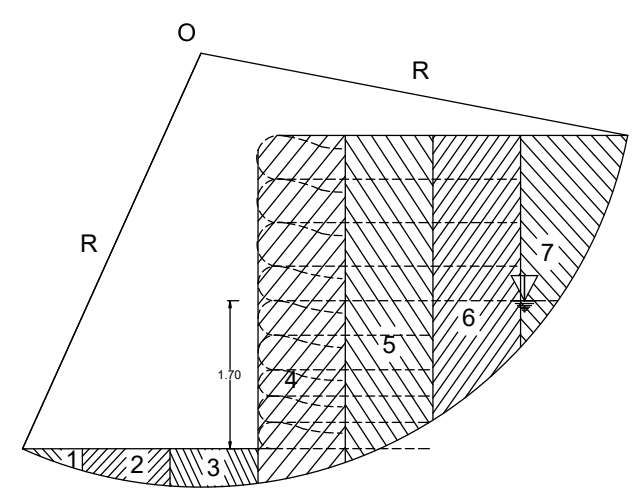

Gambar 11. Pembagian Pias pada Lereng
Tabel 4. Perhitungan FS $_{\text {non-perkuatan dengan }}$ metode Bishop

\begin{tabular}{|l|l|l|l|l|l|l|}
\hline $\begin{array}{l}\text { Pias } \\
\text { ke- }\end{array}$ & $\begin{array}{l}\mathrm{b} \\
\text { Pias } \\
\mathrm{m}\end{array}$ & $\begin{array}{l}\mathrm{h} \\
\text { Pias } \\
\mathrm{m}\end{array}$ & $(\mathrm{c})$ & $\begin{array}{l}\theta \\
\left(^{\circ}\right)\end{array}$ & $\begin{array}{l}(\mathrm{W} \mathrm{x} \\
\sin \theta) \\
(\mathrm{N})\end{array}$ & $\begin{array}{l}\phi \\
\left(^{\circ}\right)\end{array}$ \\
\hline 1. & 1,0 & 0,12 & 8420 & -19 & $-494,212$ & 28 \\
\hline 2. & 1,0 & 0,37 & 8420 & -9 & $-732,192$ & 28 \\
\hline 3. & 1,0 & 0,44 & 8420 & -1 & $-97,140$ & 28 \\
\hline 4. & 1,0 & 3,91 & 8420 & 12 & 10283,62 & 28 \\
\hline 5. & 1,0 & 3,55 & 8420 & 25 & 18978,73 & 28 \\
\hline 6. & 1,0 & 2,87 & 8420 & 40 & 23336,73 & 28 \\
\hline 7. & 1,0 & 1,08 & 8420 & 66 & 12480,86 & 28 \\
\hline
\end{tabular}

Tabel 5. Lanjutan perhitungan $\mathrm{FS}_{\text {non-perkuatan }}$ dengan metode Bishop

\begin{tabular}{|c|c|c|c|c|c|}
\hline $\begin{array}{c}\text { Pias } \\
\text { ke- }\end{array}$ & $\begin{array}{c}\mathrm{h} \text { Air } \\
\mathrm{m}\end{array}$ & $\begin{array}{c}\mathrm{U} \\
\mathrm{N} / \mathrm{m}^{2}\end{array}$ & $\left(\mathrm{r}_{\mathrm{u}}\right)$ & $\begin{array}{c}1-\mathrm{r}_{\mathrm{u}} \mathrm{x} \\
\tan \theta\end{array}$ & $\begin{array}{l}c . b_{i}+W_{i}\left(1-r_{u}\right) \\
\times \tan \theta^{\prime}\end{array}$ \\
\hline 1. & 0,12 & 1200 & 0,791 & 0,2095 & 8589,084 \\
\hline 2. & 0,37 & 3700 & 0,791 & 0,2095 & 8941,341 \\
\hline 3. & 0,44 & 4400 & 0,791 & 0,2095 & 9039,973 \\
\hline 4. & 2,02 & 20200 & 0,408 & 0,5916 & 23978,616 \\
\hline 5. & 1,66 & 16600 & 0,370 & 0,6304 & 23471,365 \\
\hline 6. & 0,98 & 9800 & 0,270 & 0,7301 & 22513,224 \\
\hline 7. & 0,35 & 3500 & 0,256 & 0,7438 & 13823,231 \\
\hline
\end{tabular}

Dicoba menggunakan FS $=1,865$

Tabel 6. dengan FS = 1,865

\begin{tabular}{|c|c|}
\hline $\begin{array}{c}\text { Pias } \\
\text { ke- }\end{array}$ & $\sum_{i=1}^{i=n}\left[c \cdot b_{i}+W_{i}\left(1-r_{u}\right) \tan \theta^{\prime}\left(\frac{1}{\cos \theta_{i}\left(1+\tan \theta_{i} \tan \phi^{\prime} / 1,865\right)}\right)\right.$ \\
\hline 1. & 10072,81 \\
\hline 2. & 9480,909 \\
\hline 3. & 9086,569 \\
\hline 4. & 23113,63 \\
\hline 5. & 22858,84 \\
\hline 6 & 23715,54 \\
\hline 7. & 20718,66 \\
\hline & $\sum=119046,98$ \\
\hline
\end{tabular}

$F S_{\text {non-perkat an }}=\frac{\sum_{i=1}^{i=n}\left[c b_{i}+W_{i}\left(1-r_{u}\right) \tan \theta^{\prime}\left(\frac{1}{\cos \theta_{i}\left(1+\tan \theta_{i} \tan \phi^{\prime} / 1,865\right)}\right)\right.}{\sum_{i=1}^{i=n} W_{i} \sin \theta_{i}}$

$$
\begin{aligned}
& F S_{\text {non-perkuatan }}=\frac{119046,98}{63756,393} \\
& =1,867
\end{aligned}
$$




$$
\begin{array}{lll}
=1,965+\left(\frac{52224,10}{41681,01}\right) & >2,0 \\
=1,9+1,25 & >2,0 \\
=3,15 & >2,0 \quad(O K)
\end{array}
$$

\section{Kontrol Stabilitas Internal}

Faktor Keamanan Terhadap Putusnya Perkuatan Geotekstil

Hasil perhitungan dapat dilihat pada tabel 7 . berikut.

Tabel 7. Perhitungan kontrol putusnya perkuatan

\begin{tabular}{|c|c|c|c|c|c|}
\hline $\begin{array}{l}\text { Lapi } \\
\text { san }\end{array}$ & Sv (m) & $\begin{array}{c}\mathrm{T}_{\text {all }} \\
(\mathrm{N} / \mathrm{m})\end{array}$ & $\begin{array}{c}\mathrm{T}_{\text {pendorong }} \\
\sigma_{\mathrm{h}} \mathrm{S}_{\mathrm{v}} \\
(\mathrm{N} / \mathrm{m})\end{array}$ & $\mathrm{FK}_{\mathrm{os}}$ & $\begin{array}{l}\text { Kontrol } \\
\mathrm{FK}_{\mathrm{os}}>3 \\
=\mathrm{OK}\end{array}$ \\
\hline 1. & 0,50 & 35000 & 3207,31 & 17,14 & $\mathrm{OK}$ \\
\hline 2. & 1,00 & 35000 & 5497,77 & 10,01 & $\mathrm{OK}$ \\
\hline 3. & 1,50 & 35000 & 7777,05 & 7,07 & $\mathrm{OK}$ \\
\hline 4. & 1,90 & 35000 & 7678,53 & 7,16 & $\mathrm{OK}$ \\
\hline 5. & 2,30 & 35000 & 10888,89 & 5,05 & $\mathrm{OK}$ \\
\hline 6. & 2,70 & 35000 & 14100,16 & 3,90 & $\mathrm{OK}$ \\
\hline 7. & 3,00 & 35000 & 12381,89 & 4,44 & $\mathrm{OK}$ \\
\hline 8. & 3,30 & 35000 & 14188,96 & 3,88 & $\mathrm{OK}$ \\
\hline 9. & 3,60 & 35000 & 15996,27 & 3,44 & $\mathrm{OK}$ \\
\hline
\end{tabular}

Faktor

Keamanan

Terhadap

Tercabutnya Perkuatan

Ditinjau Perkuatan pada lapisan ke-1, dengan $\mathrm{z}=\mathbf{0 , 5 0}$ meter

$$
F K_{P O}=\frac{2 \times\left(L-\left(\tan \left(45^{\circ}-\phi / 2\right) \times(H-z)\right)\right) \times \sigma_{v}^{\prime} \times \tan \delta}{\sigma_{h}^{\prime} \times S_{v}}
$$

$=\frac{2 \times\left(3-\left(\tan \left(45^{\circ}-28^{\circ} / 2\right) \times(3,6-0,5)\right)\right) \times 12650 \times 0,50 \times 0,355}{6416,618 \times 0,50}>1,50$

$=\frac{5119,46}{3208,31}>1,50$

$=1,596>1,50 \quad(O K)$

Hasil lengkapnya dapat dilihat pada tabel 8 . berikut.
Tabel 8. Perhitungan kontrol tercabutnya perkuatan

\begin{tabular}{|c|c|c|c|c|c|}
\hline $\begin{array}{c}\text { Lapi } \\
\text { san }\end{array}$ & $\begin{array}{c}\mathrm{z} \\
(\mathrm{m})\end{array}$ & $\begin{array}{c}\mathrm{T}_{\text {penahan }} \\
(\mathrm{N} / \mathrm{m})\end{array}$ & $\begin{array}{c}\mathrm{T}_{\text {pendorong }} \\
(\mathrm{N} / \mathrm{m})\end{array}$ & $\mathrm{FK}_{\mathrm{PO}}$ & $\begin{array}{c}\mathrm{FK}_{\mathrm{PO}}> \\
1,5= \\
\mathrm{OK}\end{array}$ \\
\hline 1. & 0,5 & 5119,46 & 3208,31 & 1,596 & $\mathrm{OK}$ \\
\hline 2. & 1,0 & 12933,36 & 5497,77 & 2,35 & $\mathrm{OK}$ \\
\hline 3. & 1,5 & 23441,72 & 7777,051 & 3,014 & $\mathrm{OK}$ \\
\hline 4. & 1,9 & 33788,40 & 7678,53 & 4,40 & $\mathrm{OK}$ \\
\hline 5. & 2,3 & 45859,54 & 10888,89 & 4,51 & $\mathrm{OK}$ \\
\hline 6. & 2,7 & 59655,12 & 14100,16 & 4,231 & $\mathrm{OK}$ \\
\hline 7. & 3,0 & 71133,48 & 12381,89 & 5,745 & $\mathrm{OK}$ \\
\hline 8. & 3,3 & 83581,84 & 14188,96 & 5,89 & $\mathrm{OK}$ \\
\hline 9. & 3,6 & 97000,2 & 15996,27 & 6,064 & $\mathrm{OK}$ \\
\hline
\end{tabular}

\section{SIMPULAN DAN SARAN}

\section{Simpulan}

a) Hasil analisis desain

1. Kekuatan tarik dari geotekstil woven tipe BW-250 yang digunakan adalah $55 \mathrm{kN} / \mathrm{m}$.

2. Tegangan izin $\left(\mathrm{T}_{\text {all }}\right)$ diperoleh sebesar $16700 \mathrm{~N} / \mathrm{m}$.

3. Spasi Antar Lapisan Geosintetik didapatkan hasil sebagai berikut :

$\mathrm{S}_{\mathrm{v}}=0,50 \mathrm{~m}$ pada $\mathrm{h} 0,50 \mathrm{~m}, 1,00$, dan $1,50 \mathrm{~m}$.

$\mathrm{S}_{\mathrm{v}}=0,40 \mathrm{~m}$ pada $\mathrm{h} 1,90 \mathrm{~m}, 2,30 \mathrm{~m}$ $2,70 \mathrm{~m}$

$\mathrm{S}_{\mathrm{v}}=0,30 \mathrm{~m}$ pada $\mathrm{h} 3,00 \mathrm{~m}, 3,30 \mathrm{~m}$, $3,60 \mathrm{~m}$.

4. Panjang perkuatan geotekstil dicantumkan pada tabel di bawah.

\begin{tabular}{|l|l|l|l|l|l|}
\hline $\begin{array}{l}\mathrm{Sv} \\
(\mathrm{m})\end{array}$ & $\begin{array}{l}\mathrm{L}_{\mathrm{e}} \\
(\mathrm{m})\end{array}$ & $\begin{array}{l}\mathrm{L}_{\mathrm{e}} \\
\mathrm{min} \\
(\mathrm{m})\end{array}$ & $\begin{array}{l}\mathrm{L}_{\mathrm{r}} \\
(\mathrm{m})\end{array}$ & $\begin{array}{l}\mathrm{L} \\
(\mathrm{m})\end{array}$ & $\begin{array}{l}\mathrm{L} \\
\text { dipakai } \\
(\mathrm{m})\end{array}$ \\
\hline 0,50 & 0,045 & 1,00 & 1,86 & 2,86 & 3,00 \\
\hline 0,50 & 0,066 & 1,00 & 1,56 & 2,56 & 3,00 \\
\hline 0,50 & 0,090 & 1,00 & 1,26 & 2,26 & 3,00 \\
\hline 0,40 & 0,095 & 1,00 & 1,02 & 2,02 & 3,00 \\
\hline 0,40 & 0,120 & 1,00 & 0,78 & 1,78 & 2,00 \\
\hline 0,40 & 0,132 & 1,00 & 0,54 & 1,54 & 2,00 \\
\hline 0,30 & 0,141 & 1,00 & 0,36 & 1,36 & 2,00 \\
\hline 0,30 & 0,156 & 1,00 & 0,18 & 1,18 & 2,00 \\
\hline 0,30 & 0,174 & 1,00 & 0,00 & 1,00 & 2,00 \\
\hline
\end{tabular}

\section{Saran}

Berdasarkan hasil desain yang diperoleh dalam penelitian ini, maka dapat diberikan saran yaitu metode yang dipakai dalam 
desain tidak hanya dengan metode Rankine. Bisa juga memakai metode metode satu baji (single wedge method) dan dua baji (two part wedge method) ataupun dengan penggunaan software seperti Geoslope agar nantinya hasil masing-masing metode dapat dibandingkan sehingga didapatkan hasil akhir yang paling efisien untuk kasus longsor ini.

\section{Ucapan Terima Kasih}

Puji syukur kehadapan Tuhan Yang Maha Esa, karena berkat rahmat-Nya penulis dapat menyelesaikan Jurnal Ilmiah yang berjudul "Desain Penahan Tanah Dengan Perkuatan Geotekstil". Ucapan terima kasih disampaikan kepada semua pihak yang selalu memberikan dukungan baik secara langsung maupun tidak langsung dalam penyelesaian jurnal ilmiah ini

\section{DAFTAR PUSTAKA}

Badan Penanggulangan Bencana Daerah (BPBD) Kabupaten Buleleng. 2013. Titik Bencana Longsor 2012 - 2013. http://bpbd.bulelengkab.go.id/index.php ?sik=berita/Titik-BencanaLongsor.html. Diakses tanggal 28 Juli 2013.

Civiliana. 2012. Modul Pelatihan Geosintetik. http://civiliana.blogspot.com/2012/05/m odul-pelatihan-geosintetik.html. Diakses tanggal 14 Juni 2013.

Das, Braja.M. 1993. Mekanika Tanah Jilid 2. Jakarta: Penerbit Erlangga.

DPU. 2009. Pedoman Konstruksi dan Bangunan: Perencanaan dan Pelaksanaan Perkuatan Tanah dengan Geosintetik. Departemen Pekerjaan Umum (DPU), Indonesia.

Koerner, Robert M. 1990. Designing with Geosynthetics, Second Edition. New Jersey: Prentice-Hall Inc.

Redana, I Wayan. 2010. Teknik Pondasi. Denpasar: Udayana University Press.
Tempo. 2013. Longsor di Bali Tewaskan

Dua Orang. http://www.tempo.co/read/news/2013/0 2/20/058390178/Longsor-di-BaliTewaskan-Dua-Orang.html. Diakses tanggal 28 Juli 2013. 